\section{$\underset{\substack{\text { hommes } \\ \text { \& migrations }}}{ }$}

\section{Hommes \& migrations}

Revue française de référence sur les dynamiques

migratoires

$1330 \mid 2020$

1973, l'année intense

\title{
Ange Bergson Lendja Ngnemzué, Expulser les sans- papiers d'Europe. États répressifs et nécessité du maintien en démocratie
}

Karthala, Paris, 2019, 318 pages, $29 €$.

\section{Mustapha Harzoune}

\section{OpenEdition}

\section{Journals}

Édition électronique

URL : https://journals.openedition.org/hommesmigrations/11676

DOI : 10.4000/hommesmigrations. 11676

ISSN : 2262-3353

\section{Éditeur}

Musée national de l'histoire de l'immigration

Édition imprimée

Date de publication : 17 juillet 2020

Pagination : 239-240

ISBN : 978-2-919040-51-3

ISSN : $1142-852 X$

Référence électronique

Mustapha Harzoune, « Ange Bergson Lendja Ngnemzué, Expulser les sans-papiers d'Europe. États répressifs et nécessité du maintien en démocratie », Hommes \& migrations [En ligne], 1330 | 2020, mis en ligne le 01 juillet 2020, consulté le 05 janvier 2023. URL : http://journals.openedition.org/ hommesmigrations/11676; DOI : https://doi.org/10.4000/hommesmigrations.11676 


\section{Expulser les sans- papiers d'Europe. États répressifs et nécessité du maintien en démocratie}

Ange Bergson Lendja Ngnemzué, Paris, Karthala, 2019, 318 p. $29 €$.

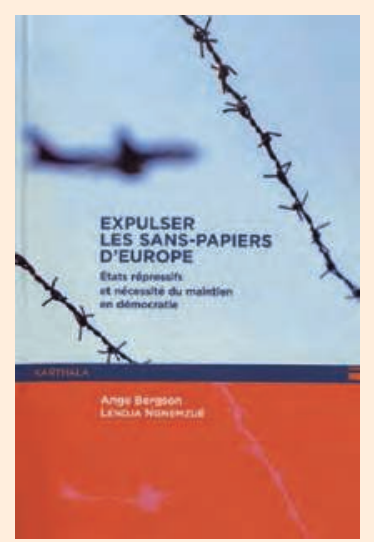

L'analyse est riche, dense, mais jargonnante et répétitive. Rigoureux en méthode et en assisse bibliographique, les références théoriques (Foucault, Giorgio Agamben ou Ernest Gellner), voisinent avec enquêtes de terrain, études historiques et données statistiques. Pour l'auteur, les expulsions des sans-papiers marquent le «retour du racisme d'État», d'un «nationalisme décomplexé», l'«incarcération de la pauvreté», et l'irruption d'une «novlangue» pour cacher la violence des «ÉTats gouvernés que sont les démocraties libérales». «Ces expulsions ne nous parlent pas des immigrés, mais de l'État», «du pouvoir souverain de décider de la circulation internationale». De ce point de vue, il n'y a pas de politique européenne mais "un simple renouveau dans les technologies policières de contrôle de la mobilité des étrangers dans les espaces segmentés de l'Europe des États-nations». Primat du national donc.

Historiquement, ces politiques ne s'ancrent pas dans la période 
coloniale, simple «stade de l'universalisation d'une culture nationale», mais dans la formation des États-nations qualifiée de «colonisation primordiale», de «dispositif et biopolitique à l'origine des conduites autoritaires [résumées] par l'assujettissement des populations à un territoire et la construction d'une identité nationale». Ainsi l'auteur s'applique à «dé-provincialiser» les expulsions, à déplacer la question de l'immigration (clandestine) de la page des "faits divers» "au centre des questions fondamentales $d u$ pouvoir politique contemporain ", «L'Étranger» devenant la manifestation «du contrôle des gouvernés par la national». Car ces expulsions traduisent la formation des sociétés d'arrivée «comme sociétés gouvernées» et «les sans-papiers renouvelle[nt] la surveillance et la compression des corps par l'État». Il en est de même de la xénophobie (de ses différentes manifestations nationales) renvoyée aussi à la construction nationale de cette norme, à la genèse de «l'imaginaire de l'altérité» qui fait qu'aujourd'hui des xénophobes récusent «le droit des "autres que nous" à jouir du "chez nous"».

Le clandestin sonne la «revanche de la souveraineté autoritaire». Autrement dit, l'État reprendrait des couleurs: autoritarisme, ordre et sécurité, mise à l'écart, confinement, expulsion, externalisation, coopération internationale sous conditions, encadrement policier (et «déviance»), «gouvernementalité» par la peur, etc. Pour tenir le pinceau, l'auteur pointe les "archipels anti-démocratiques» (police, administration, techno structure), qui participent à la gestion de l'immigration et grappillent «des pans entiers des domaines réservés» aux institutions démocratiques (parlement, opinion publique). Partant, « la question de la sortie de la démocratie peut se poser» puisqu'un «processus profond de dé-démocratisation» serait à l'œuvre - avec les étrangers pour premières victimes.

L'étude invite à dessaisir l'État de l'exclusivité du contrôle migratoire. "Il s'agit de penser et de théoriser une procédure de "dé-souveraineté" des expulsions de clandestins». Elle passerait par plus de pouvoir accordé au Parlement européen, par un droit au séjour confié à des délibérations citoyennes, par la refonte des relations entre États démocratiques et les périphéries de l'Europe, par faire du «cosmopolitisme» le «cadre de possibilité du processus de sociabilité et de socialisation démocratique de l'immigration ». L'auteur s'inspire de Jurgen Habermas pour esquisser une «politique fiction» où un ordre supranational européen dépasserait les cultures nationales par "la radicalisation du principe démocratique» - utopie d'une démocratie intégrale, "démocratie sans peuple» et «démocratie procédurale» - et la radicalisation de l'utopie du droit du sol: dans le cadre d'un eurocosmopolisme, "le sol-communautaire devient un espace monde, et les citoyens des citoyens du monde»...

M. H. 